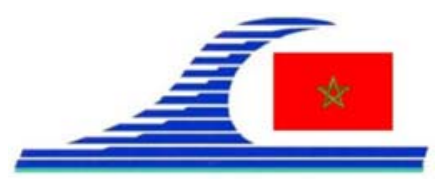

\title{
Performance of tetrahedron shaped blocks in rubble-mound breakwaters
}

\section{Fathi ESAHERI ${ }^{1}$}

1. B. Sc. civil Eng., M. Sc. Maritime Eng. Part-time Lecturer, Port consultant, The libyan University, Tripoli, Libya.

fathi_eseheri@yahoo.co.uk

\begin{abstract}
:
The first application of concrete armour blocks of parallelepiped form in the primary armouring of rubble mound breakwaters dates back to early last century. It enables engineers to design and construct flexible types of breakwaters in sites where adequate quality and quantity of natural stones are not economically available. A few years after World II, Laboratoire Dauphinois d'Hydraulique of France (1950) introduced Tetrapod armour units. Its invention revolutionised the design of rubble mound structures. A variety of complex shapes have been developed. In recent years, a single-layer approach was invented by Concrete Layer Innovations (CLI). This paper aims at evaluating the performance of tetrahedron shaped blocks from prototype observation in the main breakwater of Es Sider Harbour. In 1959, the Waterways Experiment Station (USA), tested this type, but it is of rare use, especially in the Mediterranean Sea. The objective of this paper is based on the increasing importance of the shape of armour units in rubble mound stability together with other factors. Cost-effectiveness is of major issue in this objective.
\end{abstract}

\section{Keywords:}

Rubble-mound breakwaters - Tetrahedron blocks - Es Sider - Libya

\section{Introduction}

The main breakwater of this harbour was constructed in 1961, with a length of $390 \mathrm{~m}$, with units of 5 and 10 tons located by the sea-side. The harbour suffers from excessive wave agitation and siltation inside and in the entrance. The extension of the existing breakwater is going to be investigated as one of the possible solutions to provide more protection from waves and reduce siltation in the harbour. Maintenance of the existing breakwater will be considered too. In studies carried out regarding the two main problems suffered by this harbour (DELFT HYDRAULICS LAB., 1989; ST-FA CONSTRUCTION CO., 1995a), it was concluded that those was an extreme significant wave height (Hs) of 8.4 meters over a period of 100 years, with an average wave period 8.9-11.2 sec. Water depth varies from 2.5 to 5.5 meters. An estimate of 1 meter increase in water level was considered. Due to local site orientation, wave directions in the sector 
La connaissance de la Mer :

un vecteur du développement durable en Méditerranée

between 310 and 130 degrees were considered (figure 1). The overall view of the harbour and breakwater is shown in figure 2.

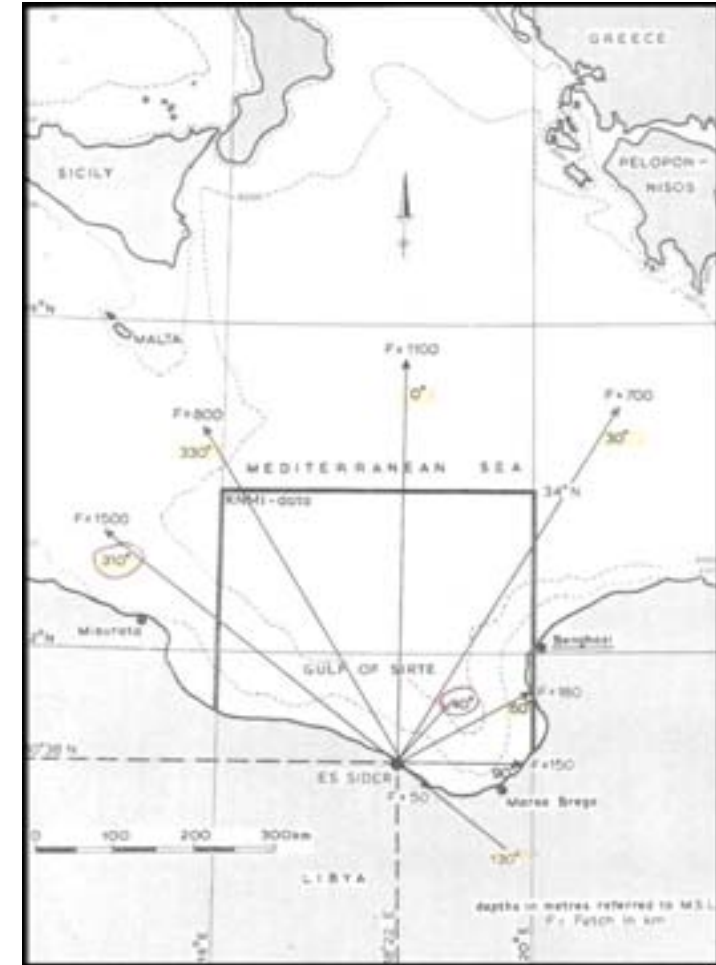

Figure 1. Location of site of Es Sider.

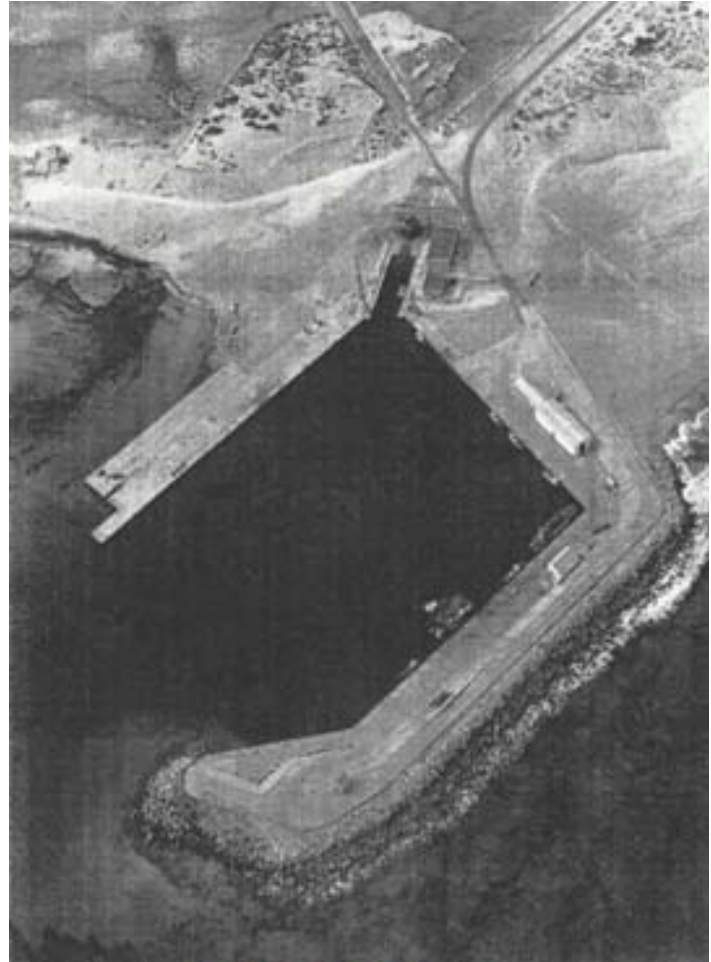

Figure 2. View of Es Sider Harbour.

\section{Brief description of the preliminary design of the proposed Breakwater}

In later studies (ST-FA CONSTRUCTION CO., 1995b), a preliminary design was made using Antifer blocks as the main primary armour for breakwater extension by length of 270 meters. Four different sections were proposed. The seaward slope of the trunk section was $1: 1.5$ and 1:2 for the head section. Crest elevation of the proposed breakwater varies from $4.8 \mathrm{~m}$ to $5.1 \mathrm{~m}$. It is worthwhile to mention that the existing breakwater crest elevation is 7.5 meters. The designer made use of previous wave climate studies with assessments and limited geophysical investigations, and recommended the verification of the design prior to construction of the project.

\section{Performance of existing breakwater}

After half a century, it is of interest to note that the geometry and shape of the cross section of the breakwater, including the section at the head, are intact (figure 3). Concrete deteriorations, cracks and breakage of some units are visible (figure 4). The overall stability draws the attention on the good performance of such units from the hydraulic point of view in a site located in the surf zone and subjected to breaking waves during the winter season in arid climate and salty weather most of the year. 
Considerable damage was reported in other breakwaters in the area, like Brega Harbour breakwater, which is only $200 \mathrm{~km}$ from, the site and Tripoli NW breakwater (BARONY et al., 1983; BARONY et al., 1987). The concrete blocks used in the primary armouring for these two harbours were of different shapes, and suffered much damage in some locations along the breakwaters, although they were constructed nearly twenty years after Es Sider. We could have assumed that design would have been more advanced. There is no intension to do direct comparison in this paper. The aim of this study is to highlight and draw the attention on tetrahedron shaped blocks. Solid or perforated, their upgrading can interest with. Artificial armour units, due to their geometry (location of C.G. and relation between volume and surface area) are simple to cast and handle, and that will reflect on the cost.

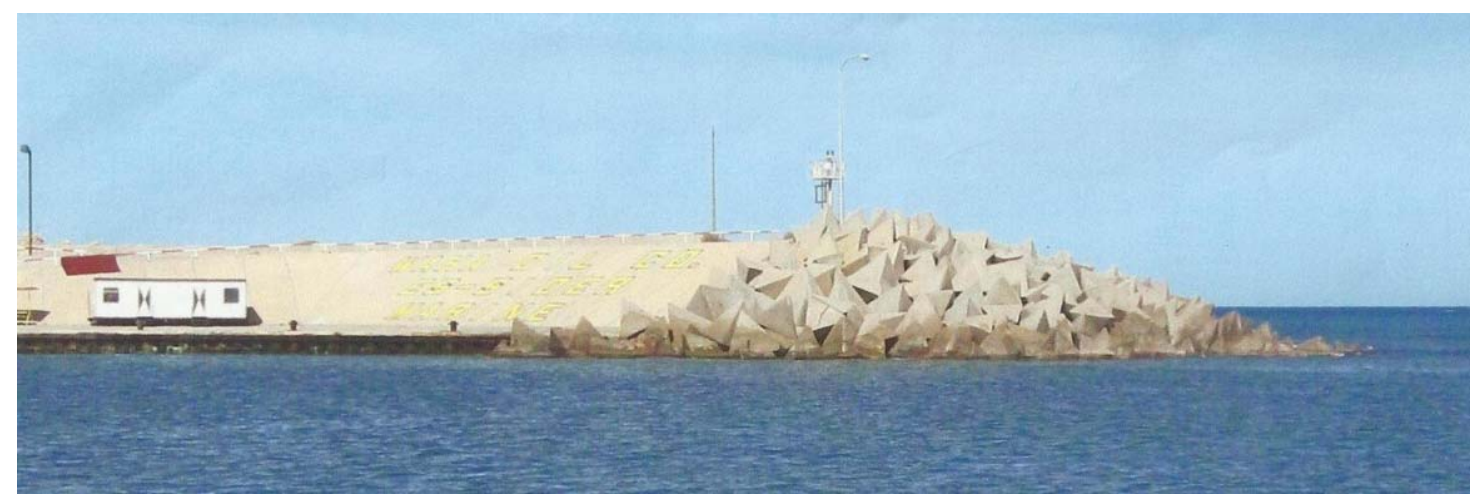

Figure 3. Photo of the breakwater, including the section at the head (16/02/2011).
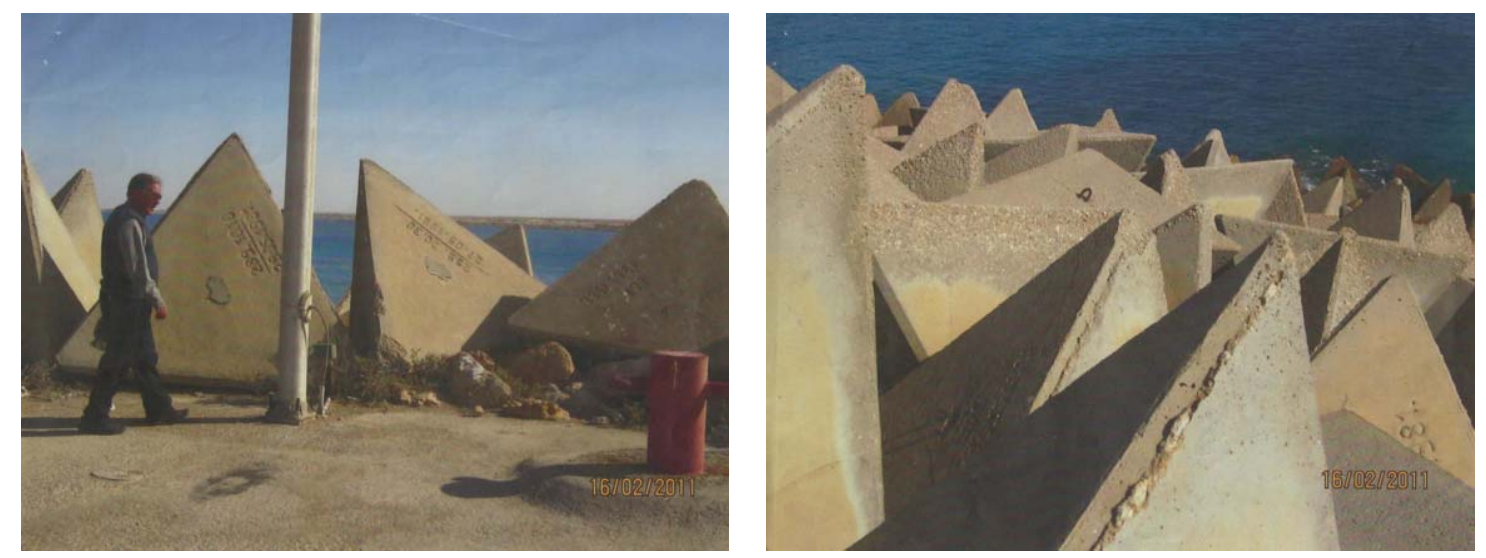

Figure 4. Photos of some of the tetrahedron units (16/02/2011).

\section{Comparison with other types}

This type of block has high void porosity, up to 63\%, and shape factor equals 1.2. The author believes (due to visual observations in many breakwater failures) that breakage of armour units due to rocking is one of the reasons that accelerate the cross-section damage, especially for slender-shaped units, like Dolos and Tetrapod, used in Sine 
La connaissance de la Mer :

un vecteur du développement durable en Méditerranée

(Portugal) and Tripoli breakwaters. Damage of some slender-type units can occur after some storms, which is not necessarily due to rocking and the wave height design. The tetrahedron blocks are less sensitive to rocking due to their geometry where its C.G is $1 / 4$ of the height from the base, and have no arms which might move during some storms and knock each other. The characteristics created by three vertices in one plane, and the forth one at a distance equal to the layer thickness (the unit height), reduce movement and increase energy dissipation on the profile, and hence contribute to stability of the breakwater section. It is possible to use tetrahedron blocks in one layer for breakwaters in unexposed locations or in some beach protection works, instead of gabions, which necessitate costly steel mesh and result in odd appearance. Special care should be given to the under-layer rock grading, when one layer is proposed. All these points should be subject to more research works and modelling to indicate more accurately the stability factor of this type of blocks for preliminarily design of rubble mound structures using Hudson or other recent formulas. The structural parameter of this type of units will contribute to better hydraulic stability of the armour layer for same sea parameters. Some other types of blocks which are commonly used nowadays can be used as reference for such research works. A criterion graph can be prepared for general use of this type of blocks after such research works. It is of interest to mention that tetrahedron blocks can be placed in uniformly "packed" pattern. Pyramid or rectangular shapes can be made on the surface of the blocks to increase the friction coefficient with rocks in the under layers.

As far as economic saving which might be achieved from employing tetrahedron blocks, the reduction in the cost of their construction, including the period of construction, can be assed and optimised in relation to other types of blocks, assuming more research work is made on this type of block and more data from prototype observations are available from other parts of the world.

\section{Tetrahedron blocks stability factor in the design formula}

Bearing in mind the use of some types of units in single layer armour with a high stability factor in recent years, it is worthwhile to mention the sensitivity of these units to progressive damage under wave attacks, especially for waves breaking on the breakwater. In some locations subjected to breaking waves and impacting forces, one should avoid the use of single layer. Tetrahedron blocks might be a good alternative as simple blocks with two layers. Their performance in Es Sider Harbour over a long period is an indication of that. Up-to date techniques in model testing, both physical and mathematical, with substantial wave climatology analysis and well-programmed site investigations will contribute to better monitoring to select a stability factor, and hence the appropriate size required.

The art of rubble-mound breakwater design which uses significant wave-height approach, from deepwater to site location, after refraction and shoaling analysis, 
necessitates care when single-layer armouring is proposed in the conception design. Indeed the repeated occurrence of some storms which induce waves higher than the significant design wave, might lead to movement of some units in the primary layer, and hence rocking and impacting of some units by others. The repeated (cyclic) dynamic wave forces on individual concrete blocks usually induce tensile stresses and consequently fatigue cracks on some units which lead to breakage. It is a step towards layer instability, leading to more damage during storms. One should not forget that duration of storms is not well represented in the design formula.

Generally, the history of failures of some breakwaters, and the relative good performance of tetrahedron blocks, is the subject of this paper. It leads the author to propose that single-layer approach should be avoided when maintenance is not easily possible, or not preferred by some clients, and that the size of the breakwater is limited. This type of block can be a substantial alternative for slender-type blocks, or singlelayer systems for some projects. Slender-type units are most often subject to movement, and, consequently, to breakage.

\section{Conclusion}

Application of single-layer approach should be avoided for breakwaters with limited sizes and located in surf zones or where initial cost-saving will be irrelevant to the costs of repairs for harbours which provide vital services like oil export. Tetrahedron blocks (solid or hollow) with adequate strength, and possible outer pyramids on their surfaces to increase their roughness, can be applied in two layers to withstand wave attack better during the economic life of rubble-mound structures. Assuming more research works will be done for better evaluation of stability factors for breaking and non-breaking cases, attention should be given to the no- damage criterion in the design approach. This criterion can be considered as the "beginning of a significant movement" in physical modelling. The building-up of damage in repeated storms should be assessed. Care and attention to provide concrete with adequate tensile stress for the block during modelling or manufacture should be considered. Revision of some prototype observations from other sites where tetrahedron blocks are used might contribute to more assessments.

\section{References}

BARONY S.Y., MALLICK D.V., GOSBI M., ESAHERI F. (1983). Tripoli Harbour NW Breakwater and its Problems. $1^{\text {st }}$ Proceeding COPEDEC Srilanka, Colombo, March, 1983, pp 20-26.

BARONY S.Y., MALLICK D.V., ESAHERI F. (1987). Tripoli Harbour New Design Criterias and Long Term Solution. $2^{\text {nd }}$ Proceeding COPEDEC Beijing, China. 1987. DELFT HYDRULICS LAB. (1989). Es Sider Boat Harbour. Report on investigations by Delft Hydraulics Lab., December1989. 
La connaissance de la Mer :

un vecteur du développement durable en Méditerranée

ST-FA CONSTRUCTION CO. (1995a). Eng. Studies for Es Sider Slipway \& Boat harbour. Report by ST-FA construction Company, July 1995.

ST-FA CONSTRUCTION CO. (1995b). Report on Preliminary Design of Es Sider Breakwater, based on Hydraulic Model Investigations, in Technical University of Istanbul. Report by ST-FA, November 1995. 